\title{
Utilization of Finite Elements Programs and Matlab Simulink in the Study of a Special Electrical Motor
}

\author{
Olivian Chiver, Liviu Neamt, Oliviu Matei, Zoltan Erdei, Cristian Barz \\ Dept. of Electrical, Electronic and Computer Engineering \\ Technical University of Cluj-Napoca \\ Baia Mare, Romania
}

\begin{abstract}
This paper presents the study of a single-phase synchronous motor with permanent magnets (PM) using some computer programs. This motor type is used especially in household applications, and it has a low power. It is known that PM synchronous motors have a great advantage consisting in the lack of rotor losses. For this motor the starting problem has been solved performing a variable air gap under polar shoes, what determine the occurrence of the starting torque due to the fact that the axis of the rotor field created by $P M$ in the rest position differs from the axis of the stator. First the parameters of the motor have been determined by tests and finite elements (FE) simulations, without knowing the properties of the PM. At the beginning magnetostatic FE simulations have been performed and then in magnetodynamic regime. The obtained results in the two regimes are closed. Secondly, with the determined parameters, a Matlab Simulink model has been realized (this being the final goal), and the dynamic regime of the motor has been studied. The results regarding the motor speed in starting process, the current variation, are also presented and discussed.
\end{abstract}

Keywords-parameters; synchronous motor; single-phase; permanent magnet; finite elements programs; Matlab/Simulink

\section{NOMENCLATURE}

$V$ - Nominal voltage

$I$ - Total stator winding current

$I_{F e}$ - Current corresponding to the iron losses

$I_{L}$ - Magnetizing and load current

$L$ - Inductance of the stator winding

$R_{C u}$ - Resistance of the stator winding

$R_{F e}$ - Resistance corresponding to the iron losses

$v_{e}$ - Voltage induced by the rotor PM

$g_{1}$ - Large air gap

$g_{2}-$ Small air gap

$\theta_{0^{-}}$Rest position of the rotor

$\theta$ - Instant rotor position (angle between the rotor and stator axes)

$N$ - Number of turns of one stator coil

$\omega$ - Angular frequency

$\Omega$ - Rotor speed
$V_{m}$ - Maximum value of the induced voltage

$\phi_{\mathrm{rp}}$-Peak flux of the rotor PM

$J$ - Total moment of inertia of the rotor

$T_{r p}$ - Peak reluctance torque;

$T_{l}-$ Load torque

\section{INTRODUCTION}

Increasing the performance of electrical equipment is a global priority, knowing that electrical power consumption is the most important cost over the lifetime of such equipment.

On the other hand, in terms of electric motors, the new standards have already imposed minimum efficiency increase. There are possible a few ways to increase the efficiency of electrical motors and it will be mentioned some of them: the use of new materials, reducing the electrical and magnetic loads or the utilization of new constructive solutions (new types of motors).

In household appliances industry, for low power drives, that do not require speed control, are used some motors with special construction. These motors must be cheap and to provide a high efficiency. Induction motors are cheap, robust but unfortunately they have a low efficiency compared with other electrical motors. The brushless direct current motors (BLDC), switched reluctance motors (SRM) or the synchronous motors, particularly PM motors, are an alternative. BLDC and SRM require more complex control equipment and for this reason they are not used for these drives. As regarding synchronous motors, these must be singlephase type in order to be fed directly from the single-phase distribution network. For low power drives, synchronous motors with PM are preferred. But like the other synchronous motors, these do not have starting torque. In order to obtain starting torque different design solutions are used: the realization of pole shoes with some notches or achieving a tapered air gap, the utilization of the rotor with some additional permanent magnets (parking magnets) [1], [2], [4], [9]; all these constructive solutions in order to impose to the rotor a preset rest position, so the PM magnetic field axis to be unaligned with the axis of stator winding.

This paper will refer to such motor, with tapered air gap, Ushaped magnetic circuit and PM rotor, and it completes the study presented in [5]. Fig.1a shows the cross section of the motor and Fig. $1 \mathrm{~b}$ presents the electrical equivalent circuit. 


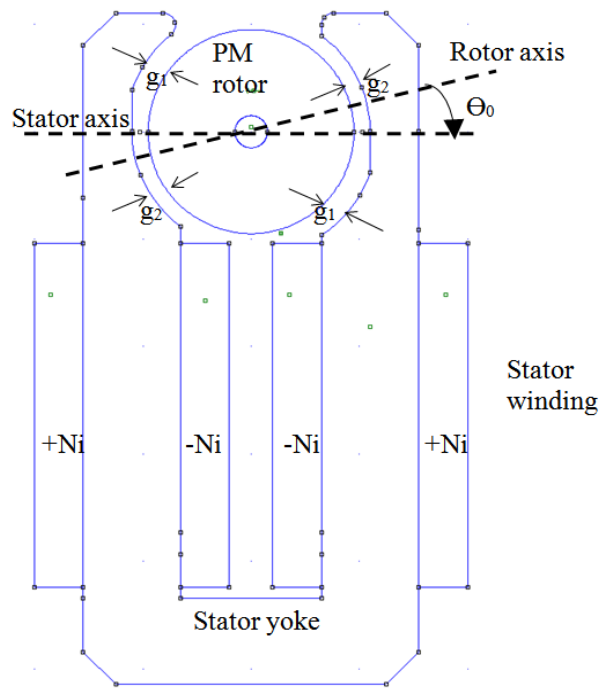

(a)

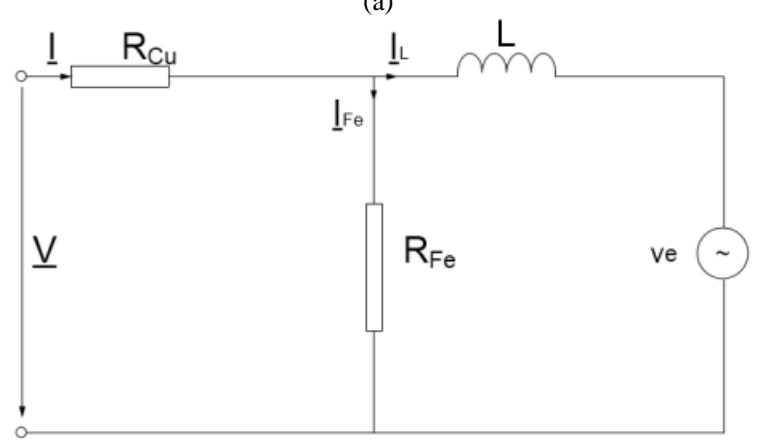

(b)

Fig. 1. Cross section of the motor; (b) Electrical equivalent circuit.[5]

For the rotor, PM with radial or parallel magnetization can be used. In the studied case the PM have parallel magnetization. The main data of PM are field coercivity, $H_{c}$ and magnetic permeability, $\mu$.

Based on electrical equivalent circuit, the motor equations can be written [1]-[3],

$$
\begin{gathered}
V=i R_{C u}+i_{F e} R_{F e} \\
i_{F e} R_{F e}=L \frac{d i_{L}}{d t}-v_{e} \\
i_{L}+i_{F e}=i
\end{gathered}
$$

The voltage induced by PM can be written in terms of the peak flux of the rotor and the rotor speed [1],

$$
v_{e}=2 \omega N \phi_{r p} \sin \left(\theta-\theta_{0}\right)
$$

And, the motion equation is,

$$
J \frac{d \Omega}{d t}=2 N i \phi_{r p} \sin \theta-T_{r p} \sin \left[2\left(\theta-\theta_{0}\right)\right]-T_{l} .
$$

In the previous equations it was assumed that the reluctance torque and the flux created by PM have a sinusoidal variation depending on the rotor position $(\theta)$. This assumption is not far from reality as will be seen in what follows.

\section{STUDY OF THE MOTOR}

\section{A. Determination of the motor parameters}

The final objective of this study is to achieve the Matlab /Simulink model of the motor. In order to perform this, the main parameters of the motor must be determined. The most important electrical parameters are stator winding resistance and inductance [6]-[8], and they were measured using a RLC meter. The resistance of the stator winding was $170 \Omega$. When the stator inductance is measured, the rotor must be at $90^{\circ}$ to the axis of the stator, so that the PM linked flux to be minimum. The rotor has to be blocked in this position during the measurements because the rotor is in unstable equilibrium. The stator winding inductance was $1.355 \mathrm{H}$. Because the rotor is blocked, the voltage induced by PM is zero and by measuring the power, current and voltage, the resistance corresponding to the iron losses can be determined. The obtained value was $11000 \Omega$.

Another very important parameter of this motor is the rest position, which can be easily obtained by FE simulations. But the problem is that the PM parameters, needed in simulations, are not known exactly, only the PM type as being Ferrite and the geometrical dimensions. In order to obtain the PM properties, the real peak flux of the PM has been determined from the voltage induced in stator winding, Fig. 2. This voltage has been recorded with an oscilloscope and the dedicated software while the main motor was driven by another same type motor.

The relation between peak flux and peak voltage derives from relation (4),

$$
\phi_{r p}=\frac{V_{m}}{2 N \omega}
$$

As the number of turns is known, the peak flux was determined, and then, more simulations have been performed with the free software FEMM (Finite Element Method Magnetics) in order to establish the suitable field coercivity.

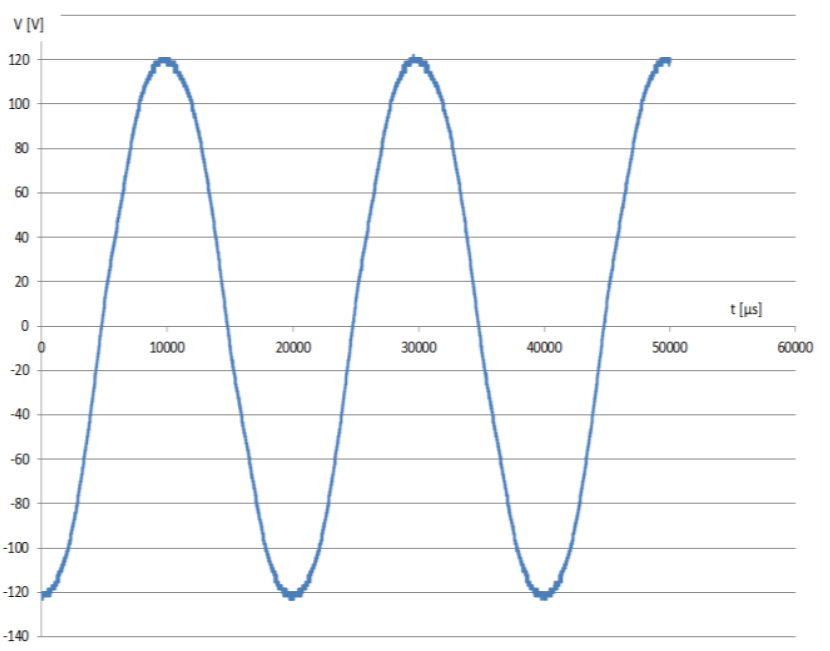

Fig. 2. Registered voltage induced in stator winding.[5]

The value of the coercivity and permeability for which the peak linkage flux is the same as the real determined value, have been considered as reference values $\left(\mathrm{H}_{\mathrm{cr}}, \mu_{\mathrm{r}}\right)$. For the magnetic 
circuit of the stator the considered material was US Steel Type 2-S 0.024-inch thickness.

The inductance of the stator winding has been determined by performing two magnetostatic FE simulations with the rotor placed at $90^{\circ}$ : first without current, Fig. 3a and the second simulation with rated current in the stator winding, Fig. 3b[5].

From the total magnetic flux (produced by PM and stator winding current) obtained from the last simulation, the flux produced only by PM (first simulation) has been subtracted and the resulted flux beeing reported to the current, the stator winding inductance has been obtained. This value was $1.38 \mathrm{H}$.

The rest position of the motor is another important parameter that must be identified by simulations. In this position the reluctance torque of the motor is zero, and the PM flux is maximum. In FEMM, the torque $M$ was obtained by Maxwell Stress Tensor Method ${ }^{1}$.

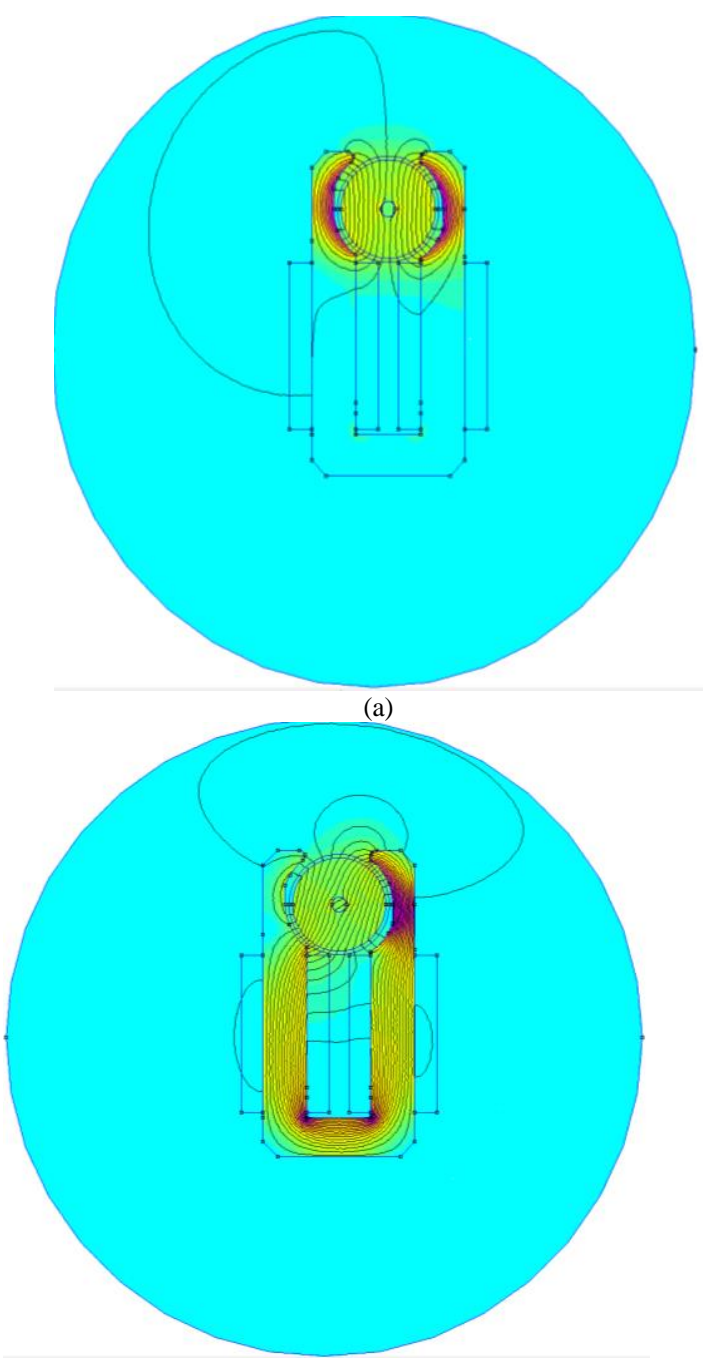

(b)

Fig. 3. FEMM simulations, flux lines and flux density map: (a) without current; (b) with rated current
The dependence of the torque by the rotor position has been obtained by performing simulations for different positions of the rotor, $\theta$ having values between $90^{\circ}$ (considering positive values toward the small air gap) to $-90^{\circ}$.

The effect of the PM properties on the reluctance torque and also on the rest position of the motor has been studied by performing simulations for different values of $\mathrm{H}_{\mathrm{c}}$ and $\mu$.

Fig. 4 shows the variation of the torque in terms of the rotor position for different values of the PM coercivity, the permeability beeing kept constant.

Fig. 5 shows the same curves, but in this case the PM coercivity is kept constant and the magnetic permeability has different values.

In both figures, continuous line has been used for the curve corresponding to the actual rotor.

From Fig. 4 and 5 it can be noticed that the motor has four positions where the reluctance torque is zero, but only two correspond to a rest position (near to $0^{\circ}$ and $180^{\circ}$ ), the rotor being in a stable equilibrium. In the other two (near to $+/-90^{\circ}$ ) the rotor is in an instable equilibrium.

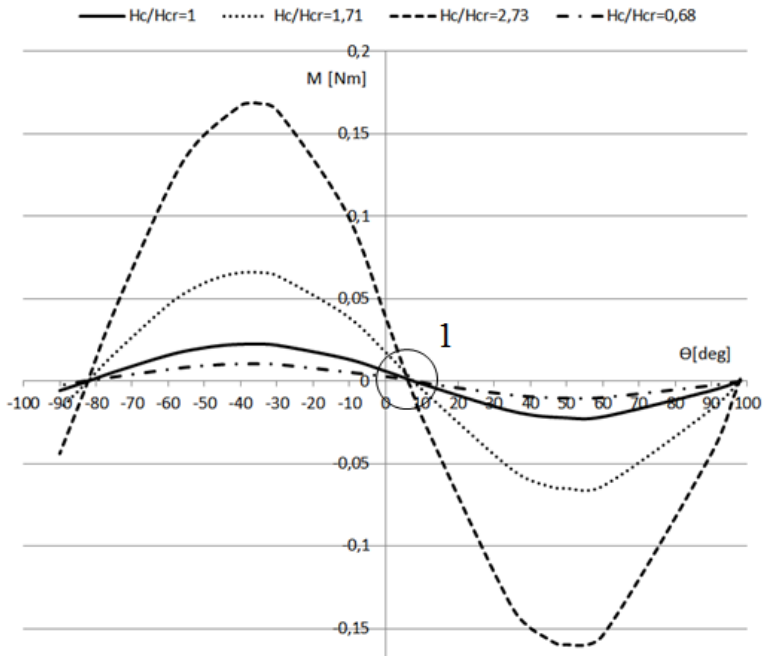

(a)

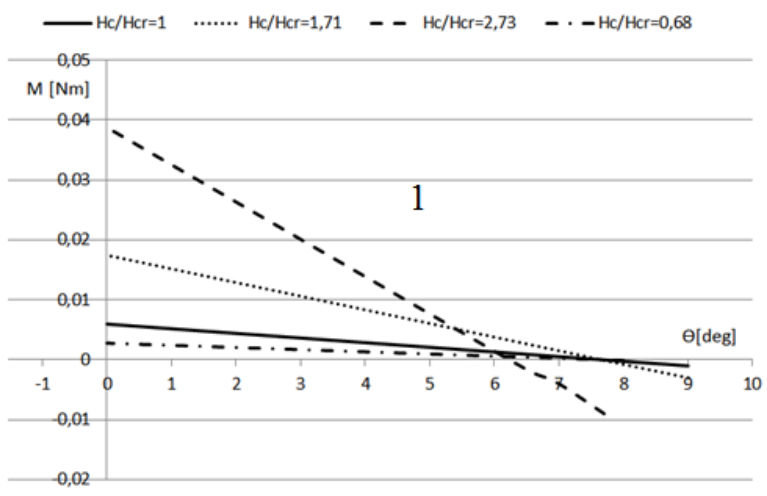

(b)

Fig. 4. Reluctance torque for different coercivities: (a) normal view; (b) enlarged view in zone 1.[5]

${ }^{1}$ Finite Element Method Magnetics.

Available online: http://www.femm.info/wiki/HomePage. 


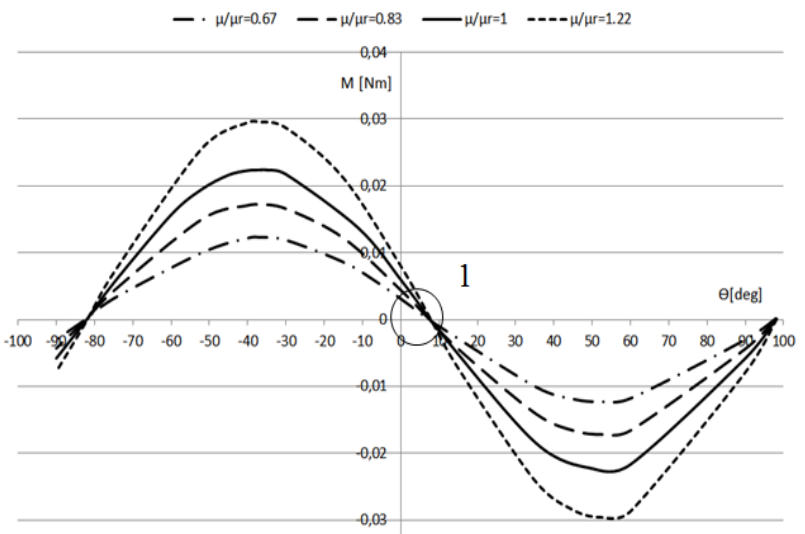

(a)
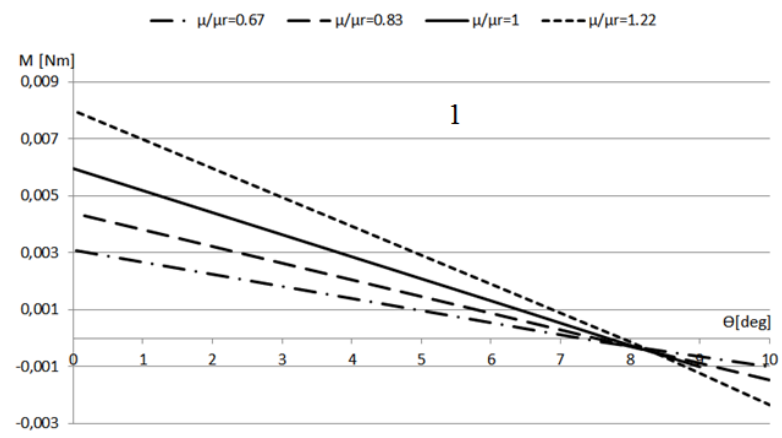

(b)

Fig. 5. Reluctance torque for different $\mu$ : (a) normal view; (b) enlarged view in zone 1.[5]

As it can be seen from Fig. 4, for different coercivities of the PM, different rest positions have been obtained. The rest position varies between $6.2^{0}$ (for the lowest $\mathrm{H}_{\mathrm{c}}$ ) and $8^{0}$ (when $\mathrm{H}_{\mathrm{c}}$ is the largest). In case of the actual rotor this angle is $7.68^{0}$, a value in accord to the literature [10], [11]. The magnetic permeability (the chosen values being specific to these magnets) has only insignificant influence on the rest position.

The resultant torque in relation with the reluctance torque for two values of the stator current is showed in Fig. 6.

The rest position has been determined also by magnetodynamic FE simulations. Two transient simulations have been made; the rotor has been set at $20^{\circ}$ and $10^{\circ}$ to the stator axis, toward the large air-gap. The rotor is left free and it moves towards the rest position and oscillates around it.

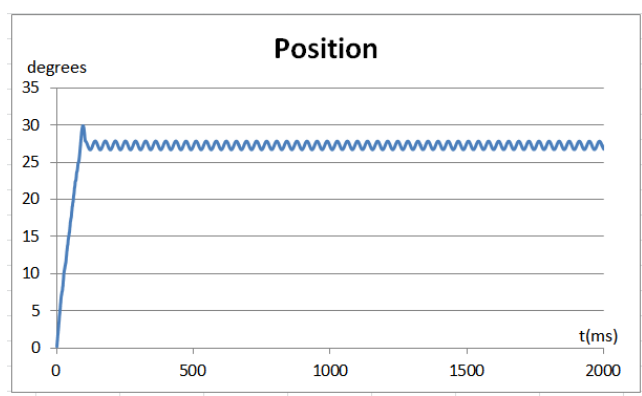

(a)

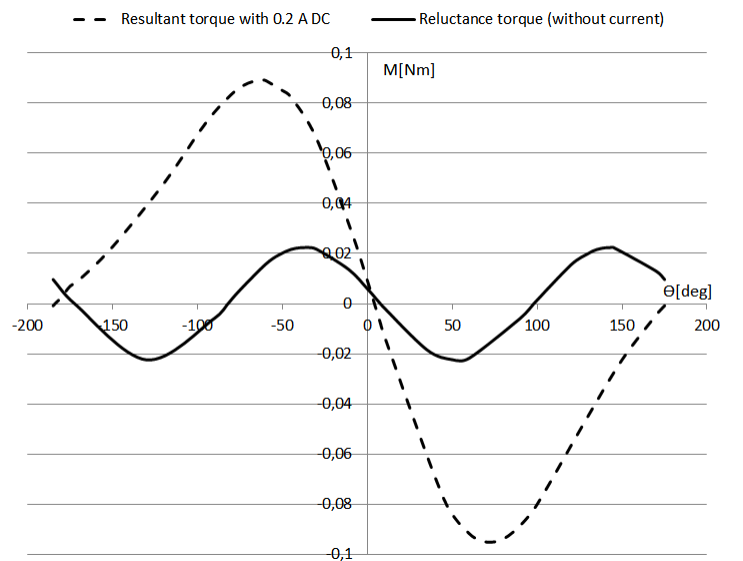

(a)

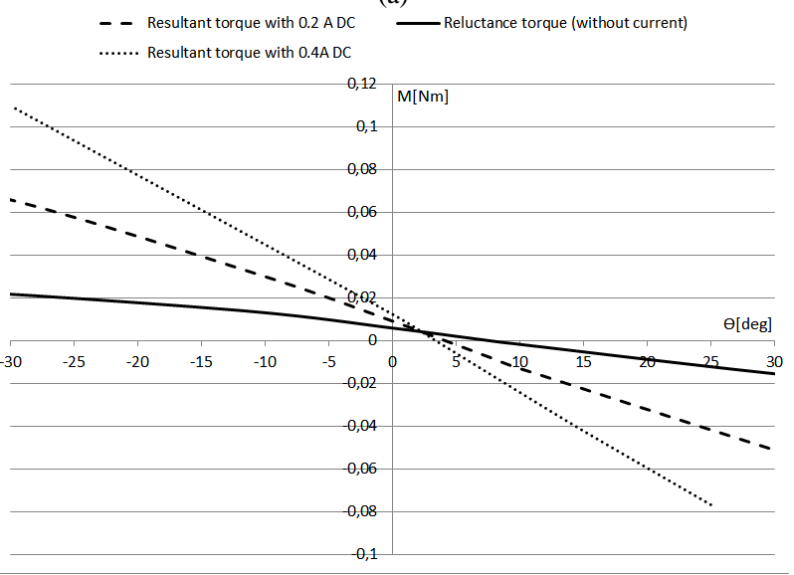

(b)

Fig. 6. Resultant and reluctance torque for: (a) $0.2 \mathrm{~A}$; (b) 0.2 and 0.4 A.[5]

To reduce the simulation time, a friction couple, opposite to movement was imposed. As is shown in Fig. 7, the rotor tends towards a position of equilibrium around 7.5 degrees from the stator axis $(7.5+20$ and $7.5+10$ respectively). Another magnetodynamic simulation has been made in order to obtain the rotor speed during starting regime. The stator winding was fed from a voltage source by industrial frequency what should determine a rotor speed of $3000 \mathrm{rev} / \mathrm{min}$ or 18000 degrees/second. Fig. 8 shows the speed variation in the first milliseconds at starting.

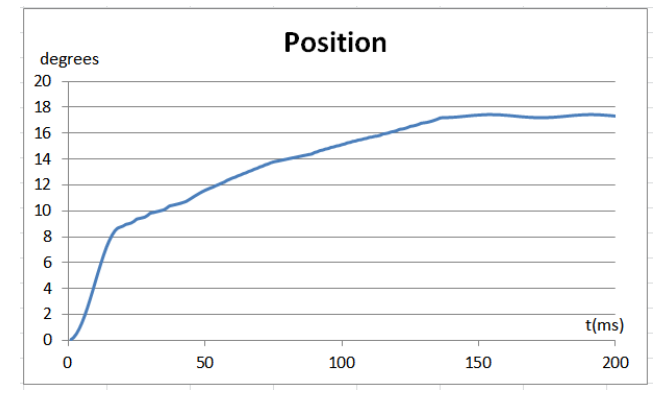

(b)

Fig. 7. The rest position determination by transient FE simulation starting from: (a) $-20^{0}$; (b) $-10^{0}$ 


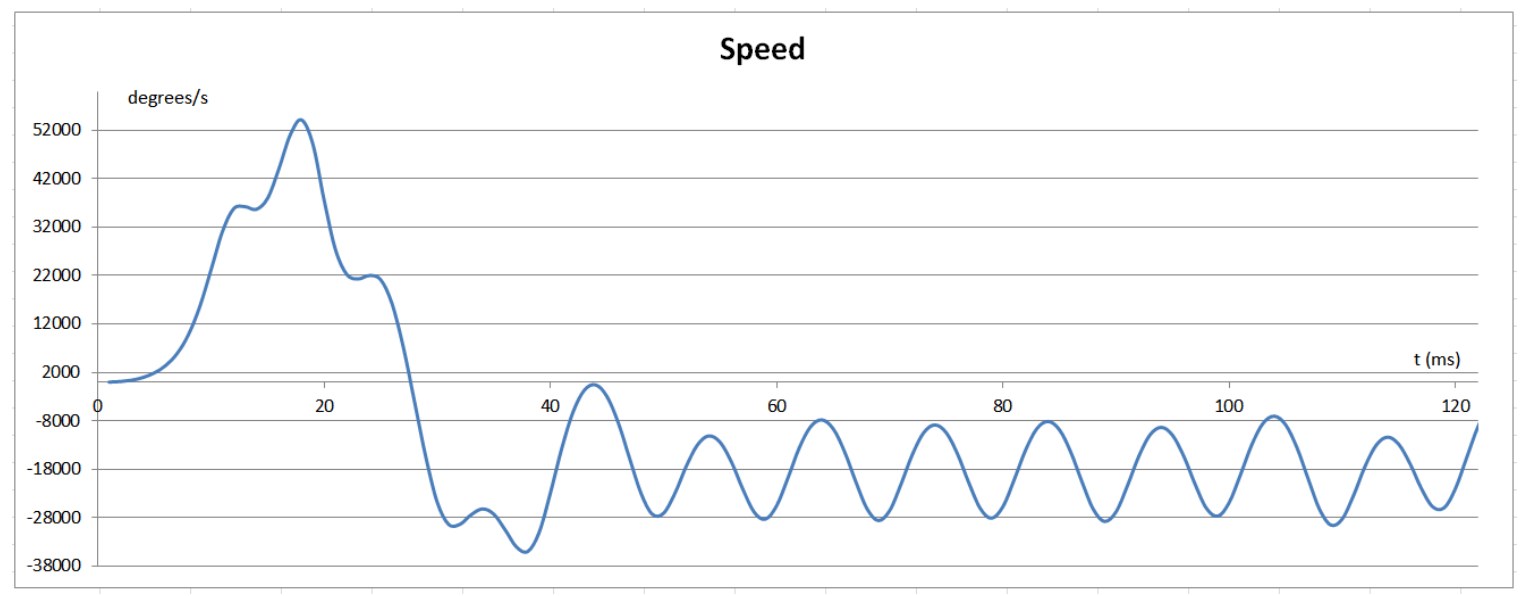

Fig. 8. Rotor speed at starting

It can be observed that the rotor moves first in opposite direction (it is considered positive direction to the left, Fig. 1) and then it reverses in the right direction, and the speed oscillates around the synchronous speed. These oscillations are quite large; one explanation could be the lack of a resistant torque.

The induced voltage was also determined by magnetodynamic FE simulation. For the rotor, synchronous speed was imposed, and the voltage induced by rotor PM was obtained and it is shown in Fig. 9. How the inductance depends on the winding current, the rotor being blocked at 90 degrees, is shown in Fig. 10. In order to obtain this, a transient simulation without motion was carried out, the stator winding being fed by a voltage source.

\section{B. Motor modeling in Simulink}

With the motor parameters determined, the model can be implemented in Matlab/Simulink. Based on motor equations, a model in Matlab/Simulink has been created, it being presented in Fig. 11.

A voltage source has been used for generation of the sinusoidal signal, and at this time the stator inductance was considered constant. The other blocks are common for Simulink. For visualization of different parameters, many oscilloscopes have been used. The simulations have been performed for five seconds, the zero moment being at starting. In the following some of the obtained results are presented.

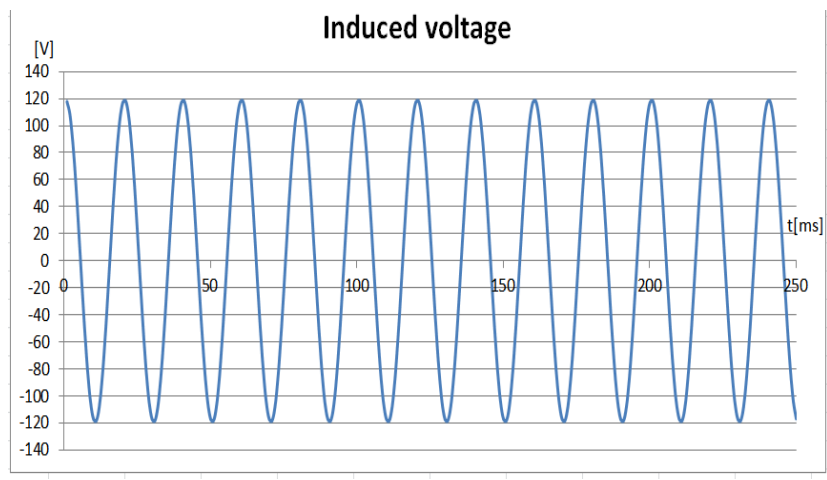

Fig. 9. Voltage induced by PM in magnetodynamic FE simulation

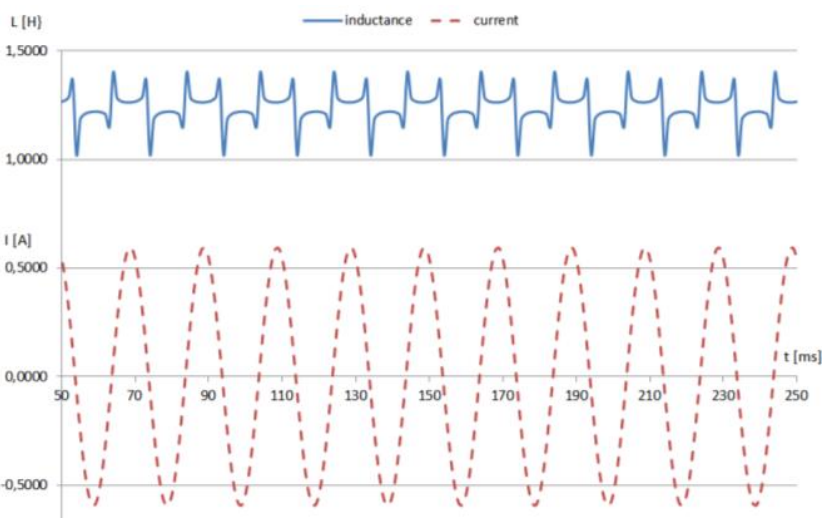

Fig. 10. Inductance dependence on the winding current

The rotor speed reaches an average speed equal with synchronous speed, Fig. 12, but there are also large oscillations. It is specified that the resistant torque imposed to the rotor was again insignificant.

The voltage induced by rotor PM is shown in Fig. 13.

The stator winding current, obtained in the following three situations: recorded, FE magnetodynamic simulation and by Simulink is shown in Fig. 14.

The recorded current and the current obtained by Simulink are in steady state operation while the current obtained by FE simulation is represented from starting to steady state.

\section{DISCUSSION}

This paper presents how the parameters of the studied motor have been identified, without knowing the properties of PM, only the geometrical dimensions were known. These properties have been determined based on the induced voltage in stator winding, recorded in no load regime. The stator winding inductance and stator winding resistance have been obtained by measurements and tests and also by FE simulations.

Another parameters as the rest position, the reluctance and resultant torque, and also the PM properties on the mentioned parameters have been studied by magnetostatic simulations. 


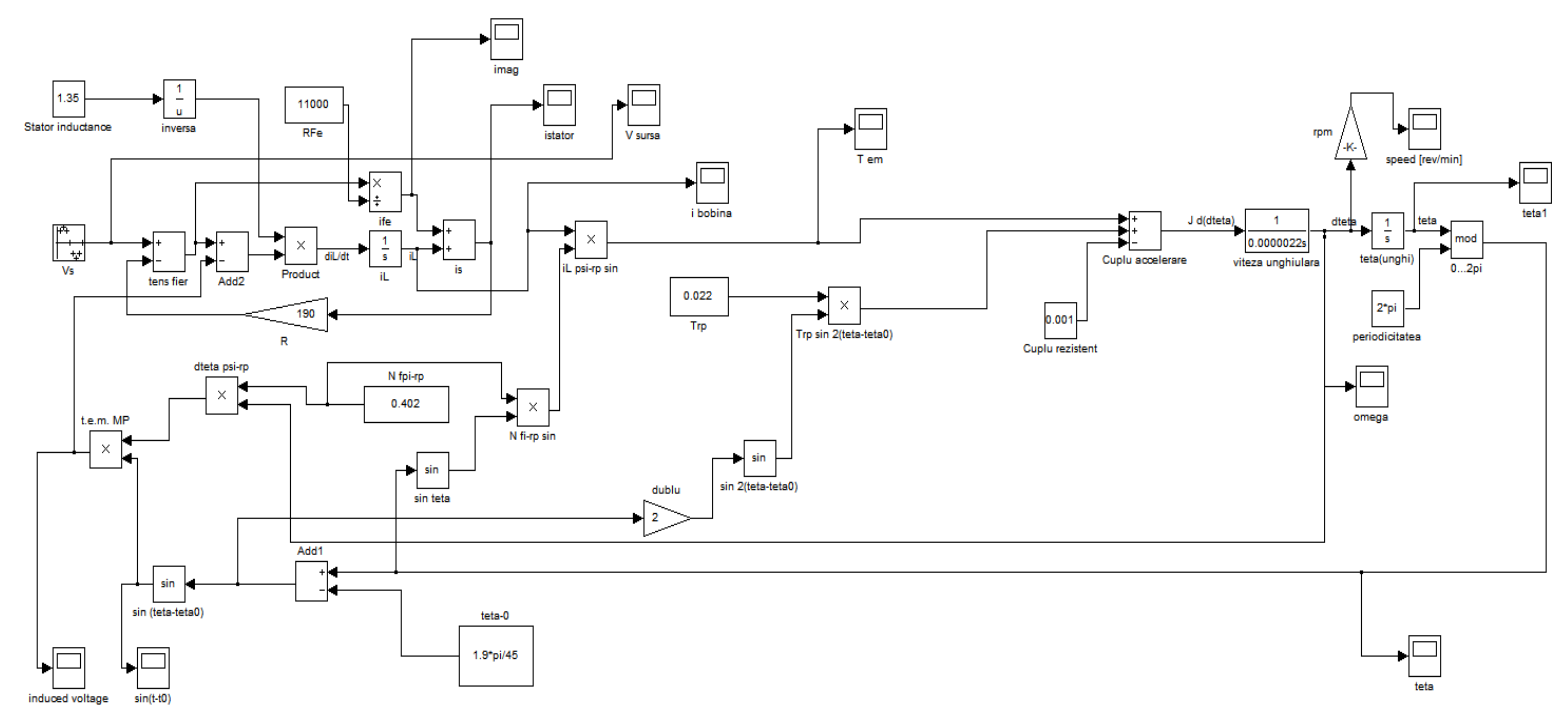

Fig. 11. Model of the motor in Simulink

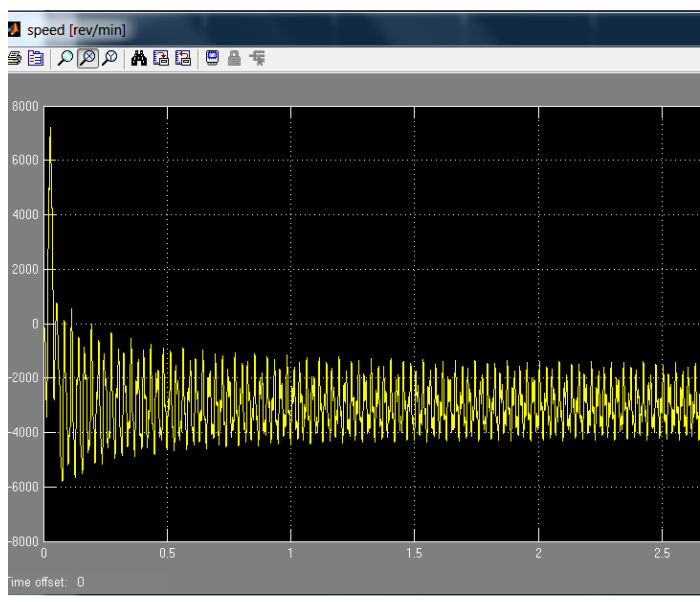

(a)

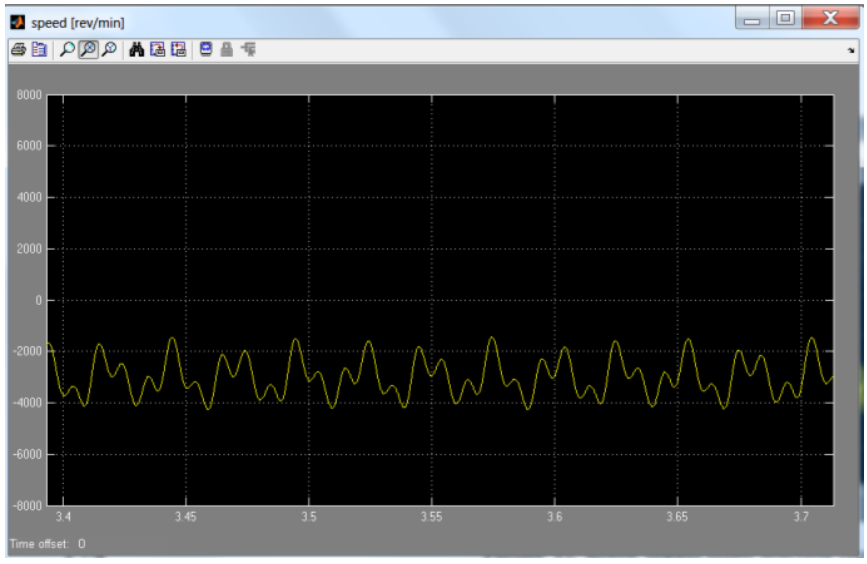

(b)

Fig. 12. Rotor speed [rev/min]: (a) from starting to steady state; (b) in steady state operation

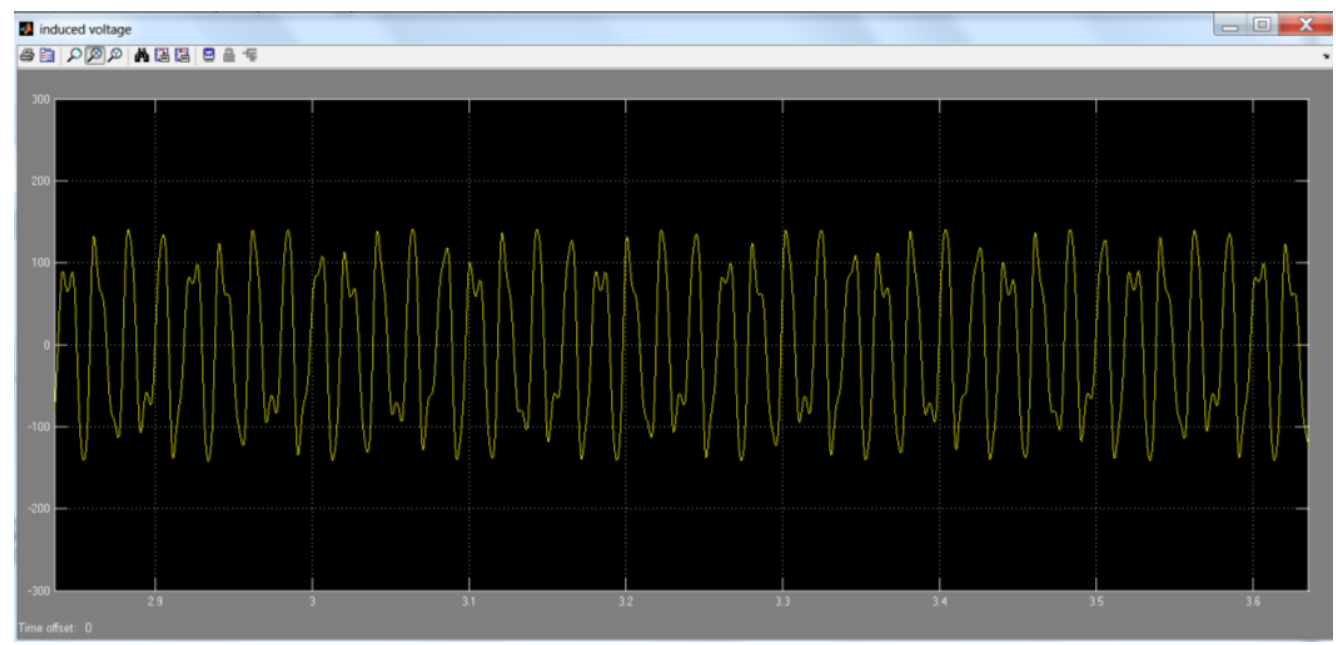

Fig. 13. Induced voltage $[\mathrm{V}]$ in steady state operation 

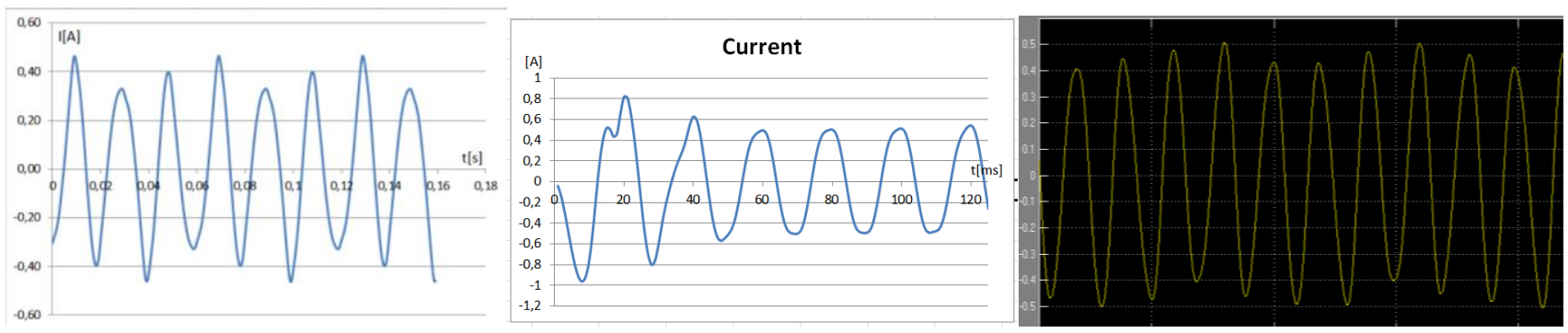

Fig. 14. Stator winding current (Amper vs. seconds): (a) recorded; (b) FE simulation; (c) Simulink

The rest position of the rotor has also been calculated by magnetodynamic simulations. In the same manner were determined the induced voltage, rotor speed and winding current.

The main purpose of this paper was to achieve in Matlab/Simulink a motor model, model that can be integrated into a system control, and replicate as accurately the actual behavior of the motor.

The FE modeling is the one that can faithfully reproduce the behavior of the motor if all designing data are known, but these programs require important hardware/time resources. And finally, the model of the motor must be integrated into a more complex system which will be carried out in Matlab, for this reason the Simulink model needs to be very accurate.

In this regard a Matlab/Simulink model of this motor was carried out. In model was used the parameters determined by tests or simulations. Some of the results obtained with Simulink were presented.

A few conclusions concerning the presented results must be done. The no load rotor speed is not constant, but the motor runs with an average speed equal to synchronous speed (3000 rev/min). This was emphasized both by FE simulations and Simulink. The measurements determined only the average speed. Although the oscillations of the rotor speed were not evidenced experimentally (measurements performed did not allow this) they are logical. While synchronous torque of the motor maintains the movement, keeping the sense, the reluctance torque periodically changes its sense; a quarter of the rotation strengthens the synchronous torque and another quarter weakens it. When synchronous torque is strengthened, the rotor accelerates and increases its speed; when synchronous torque is weakened, the rotor speed decreases. Thus, during a rotation that takes $20 \mathrm{~ms}$, the rotor speed rises and falls twice; this is seen in the speed chart, Fig. $12 \mathrm{~b}$.

The induced voltage has the same rms value, but with Simulink its form differs from the one recorded or determined by FE simulation.

The stator current variation, in no load operation, obtained by simulations, is slightly different from the one recorded.

The greater or smaller differences between results are caused by the necessary simplifications to realize the models and the impossibility of accurate reproduction of the conditions from the measurements time.
In order to improve the Simulink model, transient measurements will be required to record at the same time, the instant values of the voltage, current, speed and torque. Only in these conditions simulation results can be compared fairly with measurements.

\section{REFERENCES}

[1] H. E. Bülent H. E., D. Bülent, G. A. Capolino, "Calculation of parameters of single-phase PM motor for design optimization," IEEE Trans. on Energy Conversion, vol. 20, no. 3, pp. 538-548, September, 2005.

[2] I. L. Iepure, L. Tutelea, I. Boldea, "FEM analysis and control of a tapered airgap single phase PMSM," $11^{\text {th }}$ International Conference on Optimization of Electrical and Electronic Equipment, OPTIM 2008, May 22-14, Brașov, Romania, 2008.

[3] Fu Min, Yongsheng Yang, Yang Chen and Hongbin Jin, "Influence of step-air gap on line-start performance of u-shape single-phase permanent magnet motors," 2nd International Conference on Measurement, Information and Control, pp. 1046-1050, Harbin, China, 2013.

[4] A. Mauro, De Bortoli M., Martinelli G., Morini A. and Tortella A., "Performance assessment of a single-phase PM synchronous motor for small fan appliances," pp. 1-6, Proceedings of the International Conference on Electrical Machines, Vilamoura, Portugal, 6-9 September, 2008.

[5] O. Chiver, L. Neamt, E. Pop, C. Barz and A. V. Pop, "Identification of parameters of single-phase PM synchronous motor," Proceedings of the $16^{\text {th }}$ IEEE International Conference on Environment and Electrical Engineering, Florence, Italy, 7-10 June 2016.

[6] L. A. Pereira, E. R. Locatelli, G. Zolet and V. M. Canalli, "Single phase permanent-magnet motors - part I: Parameter determination and mathematical model," Proceedings of the IEEE International Electric Machine and Drives Conference, Cambridge, Massachusetts, June 1720, 2001.

[7] L. A. Pereira, E. R. Locatelli, G. Zolet and V. M. Canalli, "Single phase permanent-magnet motors - part II: Performance and test results," Proceedings of the IEEE International Electric Machine and Drives Conference, Cambridge, Massachusetts, June 17-20, 2001.

[8] H. E. Bülent, I. Șahin, "Evaluation of Inductance Measurement Methods for PM Machines," Proceedings of the XX $\mathrm{X}^{\mathrm{th}}$ International Conference on Electrical Machines (ICEM), Marseille, France, September 2-5, 2012.

[9] V. Ostovic, "Performance comparison of U-core and round-stator singlephase permanent-magnet motors for pump applications," IEEE Trans. on Industry Applications, vol.38, no.2, March/April 2002.

[10] G. Altenbernd, "Actual aspects of the development of fractional horsepower single phase synchronous motors with permanent magnetic rotor," Internat. Conf. on the Evolution and Modern Aspects of Synchronous Machines, Vol. 3, pp.1083-9, 1990.

[11] R. J. Strahan, "Energy conversion by permanent magnet machines and novel development of the single phase synchronous permanent magnet motor," Doctoral Thesis, University of Canterbury, Christchurch, New Zealand, September 1998. 